\title{
Analysis of chemokines and soluble adhesion molecules in cytomegalovirus-positive renal transplant recipients
}

\author{
Obeid E. Obeid and Alhusain J. Alzahrani
}

Department of Microbiology, College of Medicine, King Faisal University, Dammam, Saudi Arabia

\begin{abstract}
Background: The relationship among cytomegalovirus (CMV) infection and the serum level of chemokines and soluble adhesion molecules is not well studied. This study aimed to assess chemokines and soluble adhesion molecules in CMV-positive Saudi renal transplant recipients. Methodology: The study was conducted in a tertiary hospital in Eastern Saudi Arabia over a 12-month period. All kidney transplant recipients who regularly attended the nephrology clinics were included $(\mathrm{n}=150)$. Randomly selected age- and sex-matched individuals served as a control group $(\mathrm{n}=158)$. CMV antibodies (IgG and $\operatorname{IgM})$, chemokines and soluble adhesion molecules were measured using standard enzyme-linked immunosorbent assay (ELISA). CMV viral DNA was detected using real time polymerase chain reaction (PCR). Results: Of the 150 patients studied, $149(\mathrm{n}=150)$ had detectable levels of Anti-CMV IgG antibodies $(99.3 \%)$. In the control group, $113(\mathrm{n}=$ $158)$, blood donors had anti-CMV IgG antibodies $(71.5 \%)$. Forty-one $(\mathrm{n}=150)$ kidney transplant recipients were positive for anti-CMV IgM antibodies $(27.3 \%)$, whereas only one $(n=158)$ blood donor had detectable anti-CMV IgM antibodies. All IgM positive samples contained CMV viral DNA. MCP-1, IL-8, ICAM-1, and VCAM-1 levels were measured using ELISA. Of those, only MCP-1 and IL-8 were detectable. Eighteen kidney transplant recipients were positive for MCP-1 (12\%). All MCP-1 patients were also anti-CMV IgM positive, while 5 patients had detectable levels of IL-8 (3.3\%). All these patients were CMV IgM-positive.

Conclusions: The increase in chemokine levels during CMV infection may reflect a possible role for these molecules in the immunopathogenesis of CMV infection in this study population.
\end{abstract}

Key words: CMV, kidney transplant recipients, chemokines and soluble adhesion molecules

J Infect Dev Ctries 2010; 4(2):110-113.

(Received 19 October 2009 - Accepted 15 December 2009)

Copyright $(92010$ Obeid and Alzahrani. This is an open-access article distributed under the Creative Commons Attribution License, which permits unrestricted use, distribution, and reproduction in any medium, provided the original work is properly cited.

\section{Introduction}

Cytomegalovirus (CMV) is a persistent herpes virus with a double-stranded DNA genome [1,2]. CMV-DNA is surrounded by three layers: a tegument, a capsid with 162 protein capsomers, and an outer envelope. The principal reservoirs of CMV are fibroblasts, myeloid, and endothelial cells [3]. Although kidney transplantation is the treatment of choice for end-stage kidney disease, recipients require careful follow-up to prevent complications. Due to immunosuppressive medications kidney transplant recipients are susceptible to various infections that include CMV and others [4-10]. Transplant recipients using immunosuppressants are particularly prone to CMV disease [6, 8-9].

CMV affects $60 \%$ to $90 \%$ of healthy individuals [1]. Primary infection is often asymptomatic but can produce a clinical presentation similar to EpsteinBarr (EBV) infection with fever, myalgia, pharyngitis, cervical lymphadenopathy, mild hepatitis, and splenic enlargement. Myocarditis, pneumonitis, aseptic meningitis, and Guillain-Barré syndrome are rare manifestations [1-3]. The laboratory diagnosis of CMV infection involves routine viral diagnostic techniques. The polymerase chain reaction (PCR) test for CMV-DNA is increasingly recognized as the method of choice for diagnosis and therapy monitoring in CMV disease [1,5].

CMV infection is often associated with organ involvement, and the infiltration of leucocytes in these areas is associated with production of chemokines and up-regulation of adhesion molecules on endothelial cells and leucocytes [11]. Based on the potentially important role of chemokines and adhesion molecules in the immune response during CMV infection, these molecules could contribute to the development of infection and clinical manifestations of CMV-related disease in renal transplant recipients. The aims of this study were to determine the CMV antibodies (IgM and $\operatorname{IgG}$ ) in Saudi renal transplant recipients and control group as 
Table 1. Assessment of CMV-specific IgG and IgM antibodies in kidney transplant recipients and control group.

\begin{tabular}{|l|l|c|}
\hline & IgG positivity (\%) & IgM positivity (\%) \\
\hline Patients $(\mathrm{n}=150)$ & $149(99.3)$ & $41(27.3 \%)$ \\
\hline Controls $(\mathrm{n}=158)$ & $113(71.5 \%)$ & $1(0.63 \%)$ \\
\hline
\end{tabular}

well as the serum concentrations of the chemokines and soluble adhesion molecules (by ELISA) in CMVpositive Saudi renal transplant recipients and control group to correlate CMV positivity with chemokines and soluble adhesion molecule levels.

\section{Materials and Methods}

Study population

The study was conducted at a tertiary hospital in Eastern Saudi Arabia over a period of 12 months. All kidney transplant recipients who regularly attended the nephrology clinics were included $(n=150)$. Randomly selected age- and sex-matched individuals were recruited to serve as a control group in this study $(\mathrm{n}=158)$. Participants were provided with a clear description of the objectives of the present study and written consent was obtained.

\section{Enzyme-linked immunosorbent assay (ELISA)}

Peripheral blood samples were collected from the subjects by venepuncture in a plain tube and left to coagulate. Subsequently, fresh serum samples were isolated and immediately frozen prior to analysis. Seropositivity for CMV was determined by testing for IgM and IgG antibodies employing ELISA (Bioscience, USA). Chemokines and soluble adhesion molecules were measured in the sera of CMV-positive individuals and in the control group using standard ELISA (R\&D systems, USA) according to the manufacturer's recommendations.

\section{Polymerase chain reaction (PCR)}

CMV viral DNA was assessed by real time PCR using CMV Real-TM kit (Sacace Biotechnologies, Italy) according to the manufacturer's recommendations.

\section{Statistical analysis}

Statistical analysis was done using SPSS computer program version 9, using the students' $t$ test.

\section{Results}

Characteristics of kidney transplant recipients

The present study used the same study population of kidney transplant recipients that we used in a previous study [12]. The control group included blood donors from the same population.

Assessment of CMV antibodies in kidney transplant recipients (Table 1)

Of the 150 Saudi kidney transplant recipients included in this study, 149 had detectable levels of Anti-CMV IgG antibodies (99.3\%). In the control group ( $\mathrm{n}=158$ ), blood donors had anti-CMV IgG antibodies $(71.5 \%)$. The anti-CMV IgG positivity was significantly higher in kidney transplant recipients than in the blood donors $(\mathrm{p}=0.001)$.

As for the anti-CMV IgM antibodies, 41 ( $\mathrm{n}=$ 150) kidney transplant recipients were positive $(27.3 \%)$, whereas only one $(\mathrm{n}=158)$ blood donor had detectable anti-CMV IgM antibodies. CMV viral DNA was detected by real time PCR in all IgMpositive individuals.

Assessment of levels of chemokines and soluble adhesion molecules (Table 2)

To assess the role of chemokines and soluble adhesion molecules in the CMV-infected kidney transplant recipients, the levels of MCP-1, IL-8, ICAM-1, and VCAM-1 were measured using ELISA. Of those, only MCP-1 and IL-8 were detectable. When MCP-1 was measured, 18 kidney transplant recipients were positive for MCP-1 (12\%). All MCP1 patients were also anti-CMV IgM positive. On the other hand, 5 patients had detectable levels of IL-8 (3.3\%). All these patients were CMV IgM-positive.

Table 2. Analysis of MCP-1 and IL-8 in CMV-positive kidney transplant recipients.

\begin{tabular}{|l|l|}
\hline & No. $(\%)$ positive \\
\hline MCP-1 & $18(12 \%)$ \\
\hline IL-8 & $5(3.3 \%)$ \\
\hline
\end{tabular}

\section{Discussion}

CMV infection is common in healthy humans; however, in transplant recipients it poses a special risk and is associated with morbidity and mortality. The levels of anti-CMV IgG and IgM antibodies were assessed by ELISA. Subsequently, 149 ( $\mathrm{n}=$ 150) kidney transplant recipients had a detectable level of Anti-CMV IgG antibodies (99.3\%). In the 
control group, $113(\mathrm{n}=158)$ blood donors had antiCMV IgG antibody (71.5\%). IgG antibodies usually indicate past exposure to the antigen. The anti-CMV IgG positivity was significantly higher in kidney transplant recipients than in blood donors $(\mathrm{p}=0.001)$.

As for the anti-CMV IgM antibodies, $41(\mathrm{n}=$ 150) kidney transplant recipients were positive $(27.3 \%)$, whereas only one $(\mathrm{n}=158)$ blood donor had detectable anti-CMV IgM antibodies. Anti-CMV IgM antibodies indicate current or recent CMV infection. This was confirmed with the detection of CMV viral DNA in all IgM-positive samples. The high level of CMV infection in the transplant recipients in this study may well be due to immunosuppression. Fifty-two of the kidney transplant recipients included in this study received azathioprine and 98 patients received mycophenolate mofetil. Both of these subgroups of patients received comparable low doses of cyclosporin and prednisolone.

The published data about the prevalence of CMV infection in Saudi transplant recipients is scanty $[13,14]$. Aljurf et al. [13] determined CMV infection in 641 Saudi allogeneic bone marrow transplantation patients. Only two patients had CMV infection. Ellis et al. [14] described CMV infection in 2 out of 13 immunocompomised patients following open lung biopsy.

Chemokines are cytokines which, in addition to activating leucocytes, have specific chemo-attractive properties [15]. Up-regulated adhesion molecules on leucocytes and endothelial cells mediate the recognition, adherence and extravasations of leucocyte subsets to sites of inflammation [16]. Indeed, in vitro infection of various cells with CMV has demonstrated an effect on the production of various chemokines $[17,18]$ and on the expression of several adhesion molecules on the membrane surface $[19,20,21]$.

To assess the role of chemokines and soluble adhesion molecules in the CMV-infected kidney transplant recipients, the level of MCP-1, IL-8, ICAM-1, and VCAM-1 were measured using ELISA. Of those, only MCP-1 and IL-8 were detectable. When MCP-1 was measured, 18 kidney transplant recipients were positive for MCP-1 (12\%). All MCP1 patients were also anti-CMV IgM positive. On the other hand, five patients had detectable levels of IL-8 (3.3\%). All these patients were CMV IgM-positive. MCP-1 is a small chemokine belonging to the CC chemokine family that is also known as Chemokine (C-C motif) ligand 2 (CCL2). MCP-1 induces recruitment of monocytes, $\mathrm{T}$ lymphocytes, eosinophils, and basophils, and is responsible for many inflammatory reactions to disease. Interleukin8 (IL-8) is a chemokine produced by macrophage and other cell types such as epithelial cells. IL-8 is released to signal other immune cells to come in to the site of inflammation. The exact role played by MCP-1 and IL-8 in the pathogenesis of CMV infection in kidney transplant recipients is not clear. Both chemokines may contribute to the antiinflammatory response against CMV infection. However, if the inflammatory process is taking place in the kidney, this may lead to kidney damage and rejection of the transplanted kidney. Correlating the levels of MCP-1 and IL-8 levels with the creatinine levels and RANTES levels in CMV-positive kidney transplant recipients may well be helpful in assessing their role in kidney dysfunction [22].

\section{Conclusion}

During CMV infection, and in particular during CMV disease, a considerable increase is seen in plasma concentrations of chemokines, probably reflecting the roles of these molecules in the immunopathogenesis of CMV infection. While some of the biological effects of these multifunctional molecules may be protective, others may contribute to disease manifestations. Further studies are needed to clarify the importance of these molecules in human CMV disease.

\section{Acknowledgement}

The financial support from the Deanship of Scientific Research at King Faisal University (grant No. 7071) is gratefully acknowledged.

\section{References}

1. de la Hoz RE, Stephens G, Sherlock C (2002) Diagnosis and treatment approaches of CMV infections in adult patients. $\mathrm{J}$ Clin Virol 25 (Suppl 2): S1.

2. Boehme KW, Singh J, Perry ST, Compton T (2004) Human cytomegalovirus elicits a coordinated cellular antiviral response via envelope glycoprotein B. J Virol 78: 12021211.

3. Wang X, Huong SM, Chiu ML, Raab-Traub N, Huang ES (2003) Epidermal growth factor receptor is a cellular receptor for human cytomegalovirus. Nature 424: 456-461.

4. Humar A, Kumar D, Gilbert C, Boivin G (2003) Cytomegalovirus (CMV) glycoprotein B genotypes and response to antiviral therapy, in solid-organ-transplant recipients with CMV disease. J Infect Dis 188: 581-584.

5. Sissons JG, Carmichael AJ (2002) Clinical aspects and management of cytomegalovirus infection. J Infect 44: 7883.

6. Hibberd PL, Tolkoff-Rubin NE, Cosimi AB, Schooley RT, Isaacson $\mathrm{D}$, Doran $\mathrm{M}$, Delvecchio $\mathrm{A}$, Delmonico FL, 
Auchincloss H Jr, Rubin RH (1992) Symptomatic cytomegalovirus disease in the cytomegalovirus antibody seropositive renal transplant recipient treated with OKT3. Transplantation 53: 68-72.

7. Humar A, Uknis M, Carlone-Jambor C, Gruessner RW, Dunn DL, Matas A (1995) Cytomegalovirus disease recurrence after ganciclovir treatment in kidney and kidneypancreas transplant recipients. Transplantation 67: 94-97.

8. Hadley S, Samore MH, Lewis WD, Jenkins RL, Karchmer AW, Hammer SM (1995) Major infectious complications after orthotopic liver transplantation and comparison of outcomes in patients receiving cyclosporine or FK506 as primary immunosuppression. Transplantation 59: 851-859.

9. ter Meulen CG, Wetzels JF, Hilbrands LB (2000) The influence of mycophenolate mofetil on the incidence and severity of primary cytomegalovirus infections and disease after renal transplantation. Nephrol Dial Transplant 15: 711714.

10. Webster AC, Playford EG, Higgins G, Chapman JR, Craig J (2004) Interleukin 2 receptor antagonists for kidney transplant recipients. Cochrane Database Syst Rev CD003897.

11. Ho M. Cytomegalovirus (1991) Biology and infection. New York: Plenum Medical Book Co. 189-204.

12. Alzahrani AJ, El-Harith A., Milzer J, Obied OE, Stuhrman M, Al-Dayel A, Mohamed EA., Al-Egail S, Doud M, Chowdhury A, Guella A, Aloraifi I, Schultz TF (2005) Increased seroprevalence of human herpes virus-8 in renal transplant recipients in Saudi Arabia. Nephrology Dialysis Transplantation 20: 2532-2536.

13. Aljurf M, Gyger M, Alrajhi A, Sahovic E, Chaudhri N, Musa M, Ayoub O, Seth P, Aslam M, Al-Fiar F (1999) Mycobacterium tuberculosis infection in allogeneic bone marrow transplantation patients. Bone Marrow Transplant 24: 551-554

14. Ellis ME, Spence D, Bouchama A, Antonius J, Bazarbashi M, Khougeer F, De Vol EB (1995) Open lung biopsy provides a higher and more specific diagnostic yield compared to broncho-alveolar lavage in immunocompromised patients. Fungal Study Group. Scand J Infect Dis. 27: 157-162.

15. Baggiolini M (1998) Chemokines and leukocyte traffic. Nature 392: 565-568.

16. Springer TA (1994) Traffic signals for lymphocyte recirculation and leukocyte emigration: the multistep paradigm. Cell 76: 301-314

17. Craigen JL, Yong KL, Jordan NJ, MacCormac LP, Westwick J, Akbar N, Grundy JE (1994) Human cytomegalovirus infection up-regulates interleukin-8 gene expression and stimulates neutrophil transendothelial migration. Immunology 92: 138-145.

18. Michelson, S (1997) Interaction of human cytomegalovirus with monocytes/macrophages: a love-hate relationship. Path Biol 45: 146-158.

19. Craigen JL and Grundy JE (1996) Cytomegalovirus induced up-regulation of LFA-3 (CD58) and ICAM-1 (CD54) is a direct viral effect that is not prevented by ganciclovir or foscarnet treatment. Transplantation 62: 1102-1108.

20. Sedmak DD, Knight DA, Vook NC, Waldman JW (1994) Divergent patterns of ELAM-1, ICAM-1 and VCAM-1 expression on cytomegalovirus-infected endothelial cells. Transplantation 58: 1379-1385.

21. Nordøy I, Müller F, Nordal KP, Rollag H, Aukrust P, Frøland SS (2000. Chemokines and soluble adhesion molecules in renal transplant recipients with cytomegalovirus infection. Clin Exp Immunol 120: 333-337.

22. Weigt SS, Elashoff RM, Keane MP, Strieter RM, Gomperts BN, Xue YY, Ardehali A, Gregson AL, Kubak B, Fishbein MC, Saggar R, Ross DJ, Lynch JP 3rd, Zisman DA, Belperio JA (2008) Altered levels of CC chemokines during pulmonary CMV predict BOS and mortality post-lung transplantation. Am J Transplant 8:1512-1522.

\section{Corresponding author}

Dr. Obeid E. Obeid

Department of Microbiology, College of Medicine

King Faisal University

P.O. Box 2114

Dammam, Saudi Arabia.

Phone: +966509929487

Email: oobeid@yahoo.com

Conflict of interest: No conflict of interest is declared. 